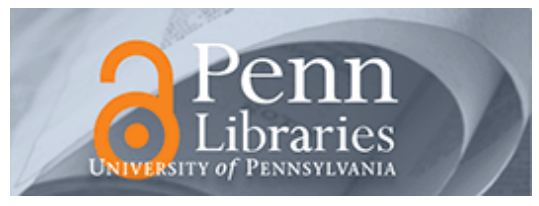

Studies in Visual Communication

Volume 10

1984

\title{
Visual Language in Science and the Exercise of Power: The Case of Cartography in Early Modern Europe
}

Chandra Mukerji

\section{Recommended Citation}

Mukerji, C. (1984). Visual Language in Science and the Exercise of Power: The Case of Cartography in Early Modern Europe. 10 (3), 30-45. Retrieved from https://repository.upenn.edu/svc/vol10/iss3/4 
Visual Language in Science and the Exercise of Power: The Case of Cartography in Early Modern Europe 


\title{
Visual Language in Science and the Exercise of Power: The Case of Cartography in Early Modern Europe
}

\author{
Chandra Mukerji
}

The so-called scientific revolution of the seventeenth century was in large part a shift toward a new kind of empiricism in science, an emphasis on observation that privileged visualization as a way of knowing. Bruno Latour's recent work on the importance of illustrations in scientific monographs returns our attention to this element in science (Latour 1982a). Latour suggests that when scientists examine visual evidence, they are often looking not at nature but at visual representations of more digested data. Graphs and charts are inspected directly and compared to one another just as plants or pollen structures might be. Equation of direct study of nature with direct study of tables and graphs in the practice of science permits scientists to manipulate each new level of analyzed data as though it were primary data; thus scientists reach new and more abstract theories with more or less the same scientific practices (Latour and Woolgar 1979; Latour 1982a).

The substitution of simple visual representations for complex sets of data allows scientists to create layered analyses, some three or four times removed from natural processes or patterns. As a result, when they think they are coming to know more about the world, they are often just coming to know more about their depictions of the world (or the systems by which they create these depictions). This is clearly true of maps, the kind of scientific system of representation that I want to discuss here. Complex measurements of location and direction are used to produce slight curves in pictures of coastlines; thousands of soundings are used to locate the ocean ridgeline in the Atlantic at a particular latitude, although this effort yields merely a point on a chart. The results are then used to study plate tectonics (in the second case) or to revise earlier models of coastlines and their formation.

In examining the ways in which the simplification of visual evidence in science is used cognitively, it is easy to overlook the way it is used to enhance the power of science in society. Information that is taken for granted in documents may be crucial to their interpretation. Outsiders, who are not schooled in the established rules of simplification, may be unable to understand or use the information in the documents. While scientists themselves do not always understand all the previously established rules of simplification, they have at least learned conventions for using them so their ignorance is no hindrance to their work (Latour and Woolgar 1979).

Chandra Mukerii is Associate Professor of Sociology and Communication at the University of California, San Diego. She is author of the book From Graven Images: Patterns of Modern Materialism, recently published by Columbia University Press.
Simplification in science, then, makes current knowledge about nature esoteric enough to be used effectively for maintaining the power of scientists as interpreters of natural processes; it is, in Foucault's terms, a technology of power (Foucault 1979). It also means that nonscientists as well as many scientists themselves are never in a position to examine the presuppositions of science that may limit its growth or areas of application. The result is that the legitimacy of science and its social functions are easier to protect from attack (Latour 1982a).

Paradigm shifts or any massive change in the rules for accumulating and simplifying evidence constitute shifts in power, since they can disrupt existing monopolies over information about nature (Foucault 1979:184-194; Foucault 1980, chap. 6). It is no mere coincidence that the rules of evidence and simplification that came to life with the "scientific revolution" were constituted after the growth of secular education and printing moved the socially legitimate study of nature from the church and into communities of scholars (Thrower 1972, chap. 6; Crone 1953, chaps. 5-6; Parry 1963:107-113; Smith 1978; Lister 1970:21-34).

Playing with the form and content of visual documents of nature can constitute, then, a ritual of power that reflects and reinforces patterns of control. This is clear in the changing form/content of cartography from the late Middle Ages to the scientific revolution. Maps had to be redrawn as shifting politico-economic rivalries accompanied the formation of the capitalist world economy. European expansion was a crucial element in the new economic system, and it both depended upon and yielded accurate geographical information. In addition, new interest in scientific geography, resulting from the revival of classical texts, helped to foster experiments in measuring land areas and projecting them on a two-dimensional surface. The interests of science and commerce combined to yield a language of cartography that on the one hand emphasized the size and shape of territo ries and on the other hand provided the navigator with tools to facilitate ocean travel. This language assumed the primacy of property and trade and thus tied scientific cartography to the emerging politicoeconomic system.

The fact that the language of maps changed radically with the growth of scientific cartography underscores the importance of Latour's attention to visual language in science. But the history of cartography also challenges Latour's idea that simplification is a peculiar hallmark of modern science (Latour 1982a). Late medieval maps are quite as simple as modern ones. The most prevalent form, the $\mathrm{T}$ and $\mathrm{O}$ map, was a simple circle divided by a $T$ shape. This form was actually replaced by much more complex imagery with the initial movement toward scientific geography. 
Only after the dimensions of scientific geography were clearly established did anything like simple medieval geometry reappear in European maps.

What this suggests is that when there is a powerful, dominant paradigm for finding meaning in nature, there can be simple images of natural forms. Simplicity in visual language is only achieved where an economy of line can convey an abundance of information. In $\mathrm{T}$ and $\mathrm{O}$ maps the form was simple, but the meaning was complex; the map was a religious icon that took for granted that the world itself was a sign of God's will.

During transition periods, when new meanings and old coexist or compete, simplicity is difficult to achieve; too many assumptions of the image-maker can be called into question. Thus information deemed relevant by nascent and dying paradigms will tend to be included in the same document. This is precisely what happened as scientific cartography was coming to life. The simple medieval map was replaced during the Renaissance by enormously complex maps, filled with the strangest bricolage of images, from careful measurements of distances to sea monsters and alchemical symbols to images of Jesus or St. Christopher $^{1}$ (Mukerji 1983; Crone 1953, chap. 8; Thrower 1972:55-60; George 1969; Schilder 1978; Pointer 1978; Lister 1970, chap. 3; Brown 1960, chap. 7).

The scientific cartography that would fit Latour's model actually appeared later, when highly ornamental works began to be replaced (as serious geography) by simpler and more specialized maps. It was in this period that cartography was returned to a world of specialists, who debated the proper measurement and presentation of information about the earth. The meaning of land as property to be controlled and used by Europeans was written into the language of maps just as the meaning of the world as a sign of God had been in the late Middle Ages. When scientific materialism was finally entrenched, ${ }^{2}$ then cartographic imagery could become both simpler and more esoteric again (Brown 1960, chaps. 9-11; Mukerii 1983; Thrower 1978, chap. 6; George 1969:39-46; Lister 1970:47-51, 75-85; Petty 1967; Taylor 1971, chaps. 10-11).

Both before the decline of medieval cartography and after the growth of scientific mapmaking, scholars used maps as sources of their authority and autonomy vis-à-vis the powerful in society. Between these two periods, scholarly cartography grew enormously, but it was not controlled by a group of specialists. European expansion made geography interesting to more people, and the new appeal of maps made possible their commercial development. They were no longer monopolized for power, but exchanged for profit. The business community as a whole did not depend on the successful monopoliza- tion of maps, so the merchants who actively developed the map trade often left the use of cartography and the definition of its forms to whoever would pay for it. Needless to say, this usually left new support for and uses of maps in the hands of the politically and economically powerful ${ }^{3}$ (see Wallis 1978; Woodward 1978;167-168; Eisenstein 1979:478-484; Schilder 1981; Pointer 1978; Lister 1970:52-75, 35-47; Brown 1960, chap. 7).

This brief sketch outlines three stages of map design in the late medieval/early modern period: (1) the early period of simple design where scholarly cosmology was in the hands of the church, (2) the period of elaborately decorated and detailed maps that accompanied commercial exploitation of maps, and (3) the beginning of simplified scientific imagery in maps. In the visual language of maps, these three stages together sketch a paradigm shift in geography that marked a change in the use of maps as a technology of power. The relative control over images, the complexity of their content, and the institutional location of their production and distribution all combined to shape three periods of cartographic image making.

\section{The Early Modern Period}

Most of the scholarly literature devoted to the social meaning of maps during the early modern period has focused almost exclusively on the way these images helped to express and regulate the relationship between Europe and the people, places, plants, animals, and wealth of the New World or the East (Bucher 1981; Elliott 1970; George 1969; Foss 1974). Certainly, pictures of Indians looking like Greek gods or shown in degraded forms or poses are emblems of European cultural domination, and the catalogs of resources recorded on European maps are a tribute both to curiosity and greed. However, they do not express the fundamental meaning of maps during expansion. Europeans did not travel to India, the Spice Islands, or the New World in search of natives and animals to master; they had those from elsewhere. They went there in search of other valuable forms of property, from gold to furs to spices to trade goods of all sorts, and in order to compete economically with other European states (Elliott 1970; Foss 1974; Wallerstein 1976; Mukerji 1983; Parry 1963, chaps. 1 and 2; Evelyn 1674; Linschoten 1598; Beaglehole 1966).

Not surprisingly, the conventional way of representing land masses in maps in the early modern period-the way that began in the Renaissance and became fundamental to scientific cartography-was a language of property; what mattered were the boundaries of continents and kingdoms rather than the sym- 
bols of their centers. Also important were the natural resources and the natural forces that made estates, trading stations, or natural waterways more accessible or useful to Europeans (George 1969; Foss 1974; Evelyn 1674)

This vocabulary of symbols is easy to overlook in the powerfully beautiful and symbolically complex maps from the transitional period in early modern cartography, ${ }^{4}$ and it is so deeply embedded in later scientific maps that it is hard to see at all. The ascendance of scientific cartography was only possible when the language of property became so basic and taken-for-granted that it lost visibility. At that point, the intellectual program of science could serve or at least not undermine the power of the social system. We can see evidence of this language if we look carefully at the "instructions" mapmakers left for the interpretation of maps, not just in legends and captions but in decoration and structure of presentation. The shape of the maps, the content of their borders, and the selection of details to fill or surround the land masses all provide a context for reading the geographical facts.

I try to interpret these elements of decoration/design here by studying in detail twelve maps and a title page to an atlas made in Europe between the late Middle Ages and the end of the seventeenth century (the period of the scientific revolution). These images are either representatives of a genre common to the period or recognized landmarks of cartography. Most of them are the latter

To try to indicate how typical the "language" of a given map is for its period or genre, I have tried to select and present here more than one of each style in order to show where I think we are facing variations on a common theme. The portolan chart is perhaps an exception, but the Catalan atlas was in many ways a member of the portolan tradition.

This choice of maps could be faulted because it consists almost entirely of landmarks, powerful images with long-term significance. But for the early period there is little alternative, because few maps from this period remain. And landmarks have an advantage in the later period, since they indicate what experiments in cartography served best the interests of those making and/or using maps. This kind of evidence is clearly insufficient to prove a thesis, but the interpretation suggested here is modest enough to be supported by it. And that is all that can be sought. The virtue of making the analysis is that it produces a three-stage model of image changes during a paradigm shift in science, and this model can be tested more systematically with contemporary evidence.

Let me begin constructing this model by pointing to a shift in the central geometry of the images from the medieval to the scientific period. Late medieval geography was written in circles. The $T$ and $O$ maps that constituted the most common form of medieval world

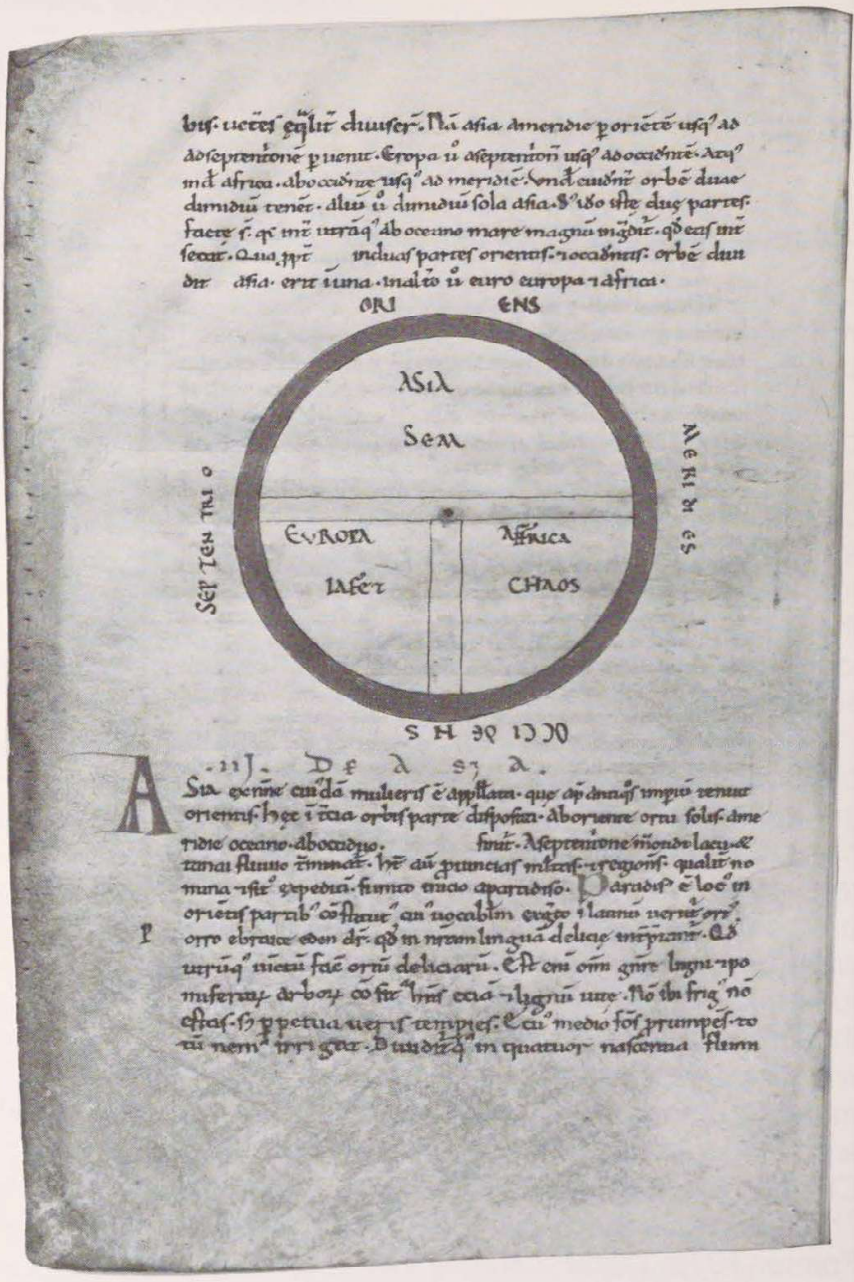

map are good examples; the other common maps of the period, portolan charts, used webs of lines radiating from compass roses to organize the information in them. In contrast, more "scientific" maps emerging from the fifteenth century relied on the rectangle as the basic map shape and the grid as the frame for internal orderliness. Borrowing ideas from Rudolf Arnheim (1982), one can argue that the circle, as an image of perfection, absolute power, the sacred, was the appropriate language for maps in an age of church domination, and that the Cartesian grid, symbolizing the profane, contestable, measurable, and impersonal, was the appropriate language for scientific domination of images of nature. Michel de Certeau (1980) argues that the change in the form of maps in this period represents a movement from a kind of self-referential imagery, one of personal vision and visionary knowledge, to a kind of impersonal and external imagery. The subjective is expressed one way in the sacred world of the $\mathrm{T}$ and $\mathrm{O}$ map, where belief triumphs over observation; it finds another form in medieval travelers' maps that list landmarks along a route instead of presenting an overview of a region Each type of medieval map is centered on the subject or subjective experience. Scientific maps, on the other hand, are presented as though they had no au- 
Figure 1 Twelfth-century $T$ and $\mathrm{O}$ map. By permission of the Bibliothèque Nationale, Paris.

Figure 2 Simple $T$ and $O$ map, fifteenth century. By permission of the

Bibliothèque Royale Albert $1^{\mathrm{er}}$, Brussels.

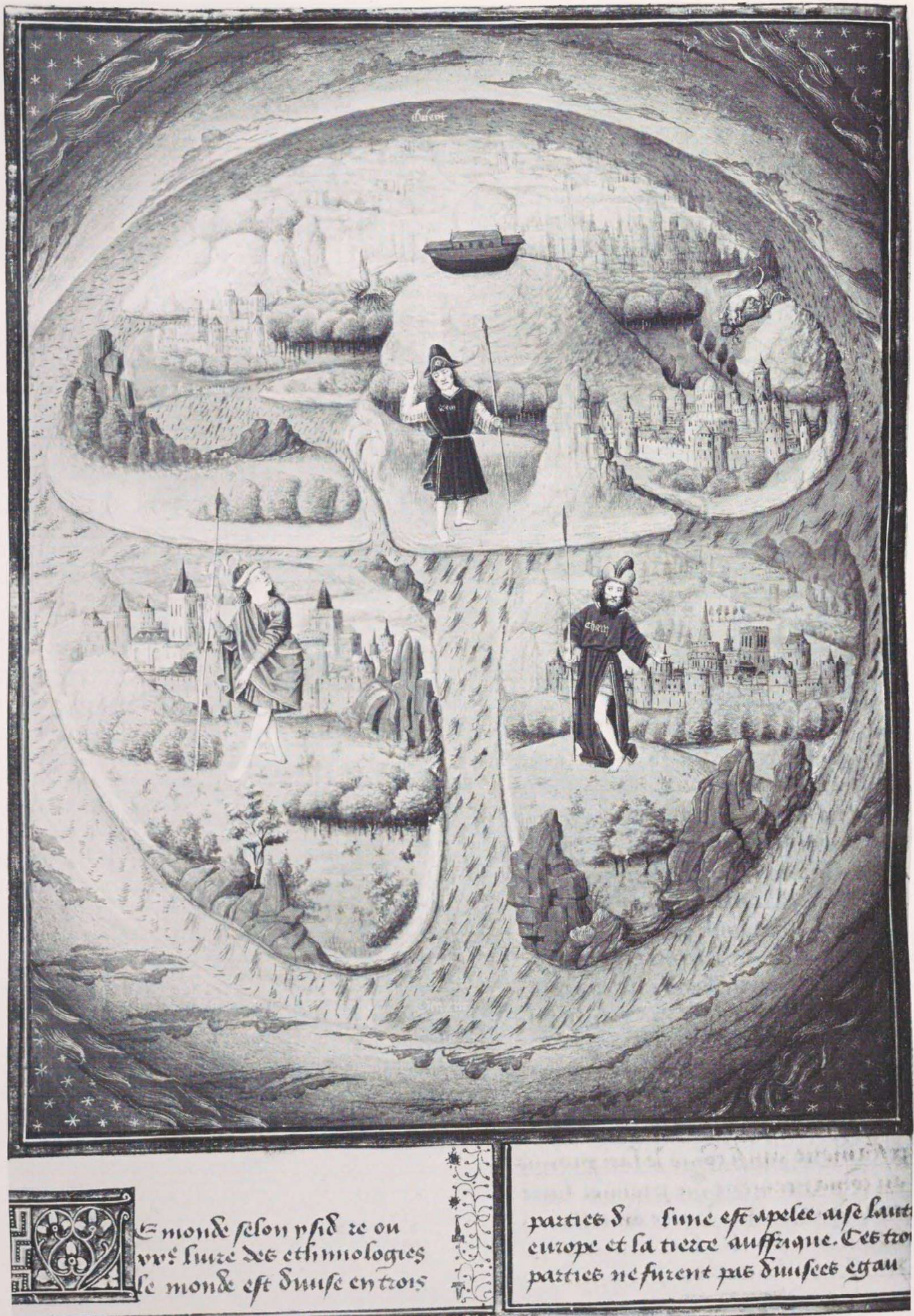


Figure 3 Detail of Ebstorf map, thirteenth century. By permission of the William L. Clements Library, University of Michigan, Ann Arbor.

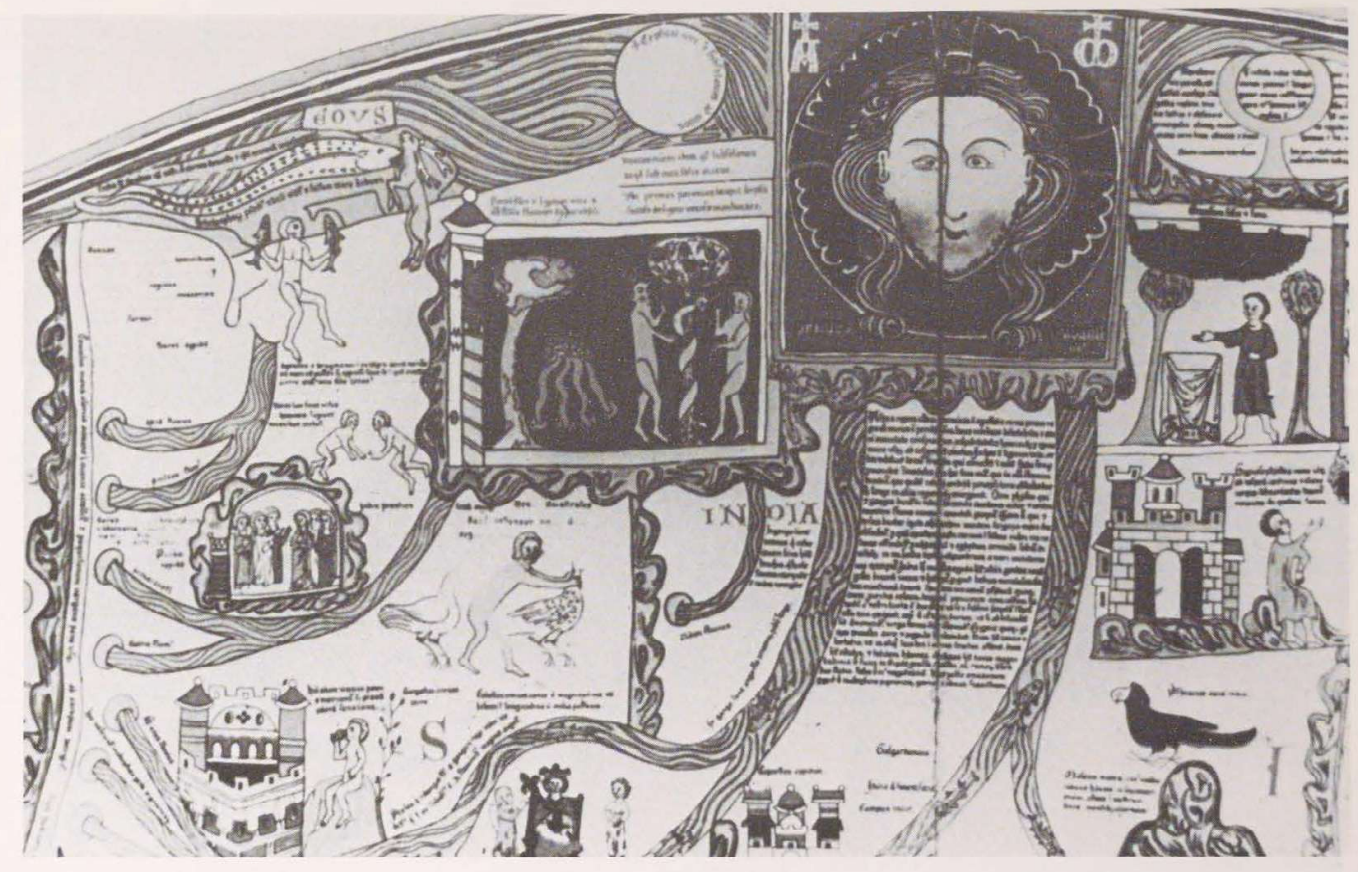

thor, only someone to decide where one map is to end and the next begin. They are defined by their borders and corners, not by the center of their circular form.

The twelfth-century $\mathrm{T}$ and $\mathrm{O}$ map illustrated in Figure 1 is a good example of its genre. We can see quite clearly in this map how depiction of land masses can be ultimately simple and yet subordinated to the sacred world of the circle and to church doctrine rather than to a scientific perspective (see Tooley 1978:12; Lister 1970:16-17). The world drawn here is a religious icon, a power symbol. It is also completely geometrical. A perfect red circle is divided into three parts by a "cross" in the shape of a T that locates Asia as the top half of the circle and divides the lower half into Europe on the left and Africa on the right. The center of the world is the map's most important mark. It is a red dot that can be read as a bloody nail at the religious center of the European world: Jerusalem. Each continent is named and given a secondary inscription. Asia is Sem; Europa is lafet; and Africa is Chaos. With this secondary naming the continents are associated with the three sons of Noah: Shem, Ham, and Japhet (see Tooley 1978:12). Three continents are symbolized as a "trinity" of figures from the Bible. This geography is on many levels an image of religious ideology.

The fifteenth-century $\mathrm{T}$ and $\mathrm{O}$ map in Figure 2 resuscitates and extends most of these themes. The three continents are depicted as three islands, each with a castle, some forests, and a single man. Presumably, these men are the three sons of Noah, each with his own kingdom/continent. The continents are surrounded by a torrent of water, apparently a remnant of the flood; and on top of a central mountain in Asia sits the ark, seemingly placed near heaven on this natural altar.
There is an irony here that words cannot adequately describe. It is not so much that this kind of religious icon lasted into the fifteenth century when European expansion was in early but full bloom; it is that the island/continents are presented with a Renaissance naturalism that seems an odd medium for carrying such a traditional message. There is a strong sense of perspective in the image of Asia; it is not scientific perspective, but it is dramatic in its successful evocation of depth. Moreover, the three male figures are dressed in rather exotic clothes reminiscent of Renaissance costume books. The empiricism that was the foundation for both Renaissance naturalism and the impulse to collect costume designs (Vecellio 1977; Baxandall 1974; Antal 1947; Burckhardt, n.d.) did not alter the iconographic depiction of geography in this map. Ecological symbolism that might have been used to distinguish continents is not evident; differences in the architecture are not inventoried; and even dress is not carefully linked to specific cultures. Old geographical symbolism is presented in a contrastingly contemporary visual language.

Traditional $\mathrm{T}$ and $\mathrm{O}$ maps were not the only form of medieval geography; they existed alongside some other more empirical images of the world. Some were clearly hybrid forms, in which a sense of empirical location intersected with fundamentally religious imagery. One of these is the Ebstorf map of the thirteenth century (Figure 3). This map distinguishes land and water as physical spaces in a circular world, vaguely differentiating three continents but not in the simple geometry of the $\mathrm{T}$ and $\mathrm{O}$ maps. The Ebstorf map depicts a more natural geographical environment, where wind and weather fashion complex shorelines and the three continents are divided by interconnecting waterways running to the Mediterranean. ${ }^{5}$ Still the map is filled with religious im- 


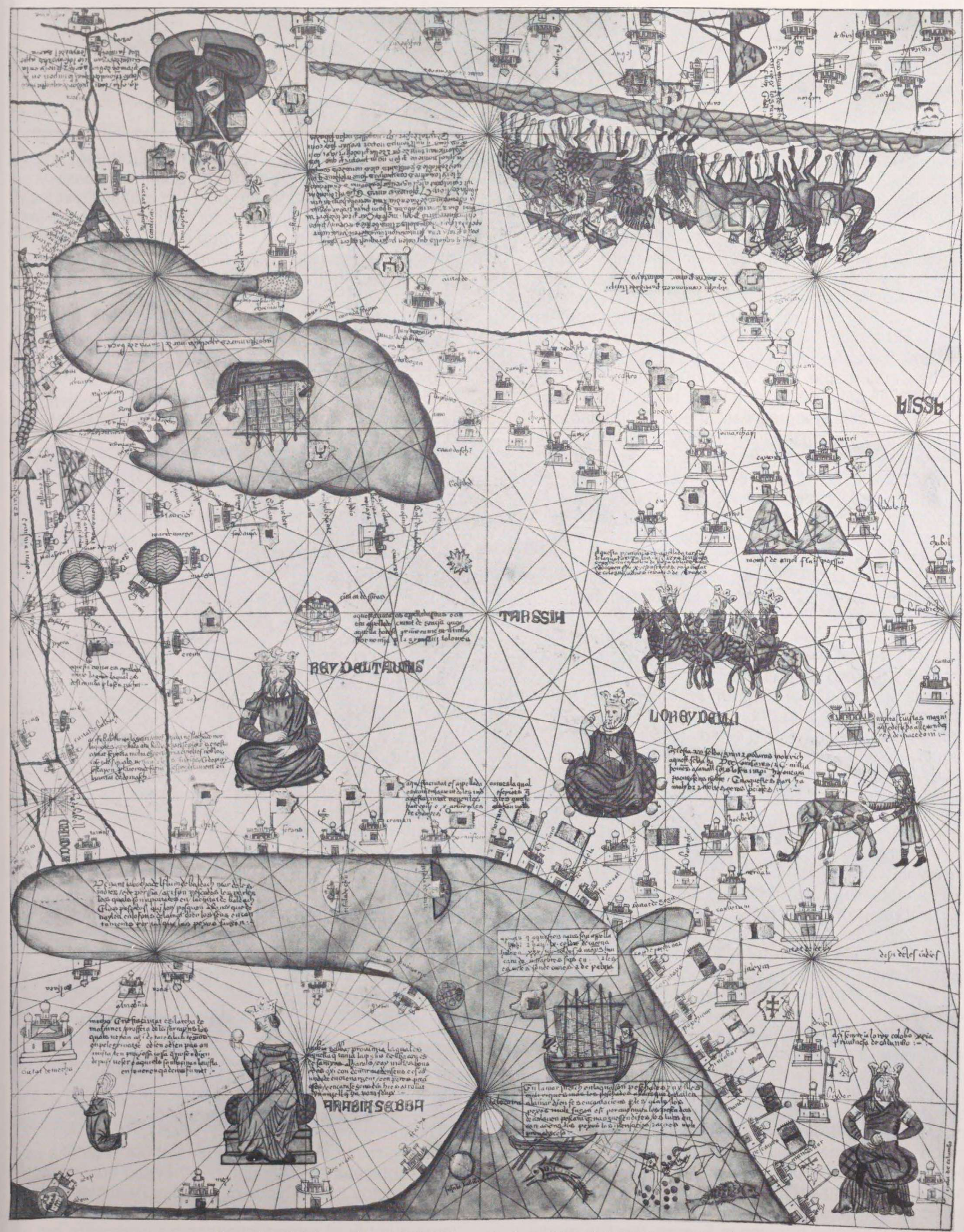

Figure 4 Catalan atlas, 1375. By permission of the British Library, London 
agery. Christ's head, hands, and feet emerge from the earth. The top half of the map depicts the East, which is still associated here with the Holy Land; this location places the East around and under the large face of Jesus; the center of the map is maintained at Jerusalem, where camel and Christ intersect; and next to the area marked India lies a picture of Adam and Eve being tempted by the snake in the garden of Eden. Allegory and geographical space coincide here in a world that is visually distinct both from the formal $\mathrm{T}$ and $\mathrm{O}$ maps and empirical maps of continents.

The Catalan atlas of 1375 (Figure 4) is at first glance not unlike the Ebstorf map, since it also depicts identifiable geographical spaces with images that seem more fanciful than empirical. Distances are not always carefully measured and reproduced, and symbols of nongeographical information abound. But while the Ebstorf map is primarily a catalog of religious beliefs, the Catalan atlas is more a vehicle for presenting the experience of medieval travelers. For one thing, the Catalan atlas drops altogether the religiously based convention of depicting the world as a circle; this map is a long rectangular shape. Religious figures are not eliminated from the map altogether, but they must share it with Marco Polo going to "Assia" with a pack of camels. The story of the end of the world is told here, as are other sacred stories; there is also a circular diagram for determining the religiously favorable and unfavorable days of the year that combines geometrical simplicity with religious significance like a T and O map. But the European coastline along both the Atlantic and Mediterranean is drawn with a geographical accuracy that any seaman routinely sailing those waters would have appreciated. The insides of the continents also show information particularly pertinent for traders: the locations of mountains, a "list" of landmarks along coasts, and a series of castles representing places to stop along major trading routes. There are even large pictures of kings who presumably control the regions around them. The world is shown here as a space to move through, with major pitfalls (like mountains, large bodies of water, and political powers) described. In this way the atlas declares itself to be a traveler's map.

At the same time, the Catalan atlas also depicts a world without conventional top or bottom; the castles and illustrations are oriented toward all sides of the map. And in spite of its empirical basis, it still remains something of an allegorical map; the traveler's tale may supplement the biblical story, but it functions as much as a source of allegory as a source of information. The simultaneous empiricism and allegorical nature of the Catalan atlas indeed reflect its two sources. On the one hand, the Catalan atlas was the heir to the portolan tradition in Europe, the late medieval practice of recording accurately the details of the European coasts that were useful and used by mariners "coasting" on those shores; on the other hand, the Catalan atlas was an attempt to add the information recorded by travelers to the East to the wellknown information from the portolan tradition. And travelers' tales are notorious for their inaccuracy. ${ }^{6}$ Looking at the image of Europe in the atlas makes this map seem very "modern" and accurate; looking at its eastern edge creates a feeling closer to that created by the Ebstorf map. This "world," like the ones dominated by religious iconography, is drawn from fanciful as well as empirical narrative.

The Roselli chart of the Mediterranean (1456), shown in Figure 5 , is useful in demonstrating the similarities between the world depicted in the Catalan atlas and other works in this tradition. For one thing, the chart is organized within a grid of lines known as rhumb lines; they radiate from a series of compass roses that ring a central rose placed (aptly enough) in the Mediterranean. In their circular arrangement these roses recreate some of the geometry of the $T$ and $O$ map in this more empirical representation of the world. This geometry stands in direct contrast to the grids of latitude and longitude derived from Greek geography and typical of modern maps. The portolan charts are travelers' maps; with the rhumb lines they provide a language of directionality for organizing the empirical information gathered in them. While later maps emphasized land and careful inventories of its size and contents, these charts drew attention to the major "roadway" of the period: coastlines. The interior spaces in the chart are like those in the Catalan atlas; the imagery used there seems more allegorical than factual. Power centers may be marked with castles and flags, but the symbolic representations are crude. The images of the interior are also oriented in different directions. They foil our attempts to see this map as rationally oriented around the two poles. The general lack of information about interiors contrasts sharply with the delicate detail of coastal landmarks and shorelines. Some late portolans, like the Joan Oliva map of 1599 , are more delicate in depicting features of the continents themselves but sustain nonetheless a strong contrast between the coastlines, jammed with information, and the interiors, spotted with occasional points of interest (Penrose, n.d. 18-19; Crone 1953:chap. 3; Lister 1970:20-21).

The portolan charts, $\mathrm{T}$ and $\mathrm{O}$ maps, and travel chronicles used to inform or shape the Catalan atlas comprised the three major strains of geographical recording that dominated medieval Europe. Another influence, the classical works, particularly the work of Ptolemy, reintroduced some ideas about scientific geographical measurement, but they did not immediately destroy the religious or portolan traditions of medieval geography. In the fifteenth century, however, a large number of reproductions of his work were put out by publishers, including the UIm Ptolemy of 1486 shown in Figure 6. They stimulated interest in devis- 
Figure 5 Roselli chart of the Mediterranean, 1456

By permission of the

Newberry Library,

Chicago.

Figure 6 World map from

Ptolemy, Cosmographia,

UIm, 1482. By permission of the Rare Book Division New York Public Library.

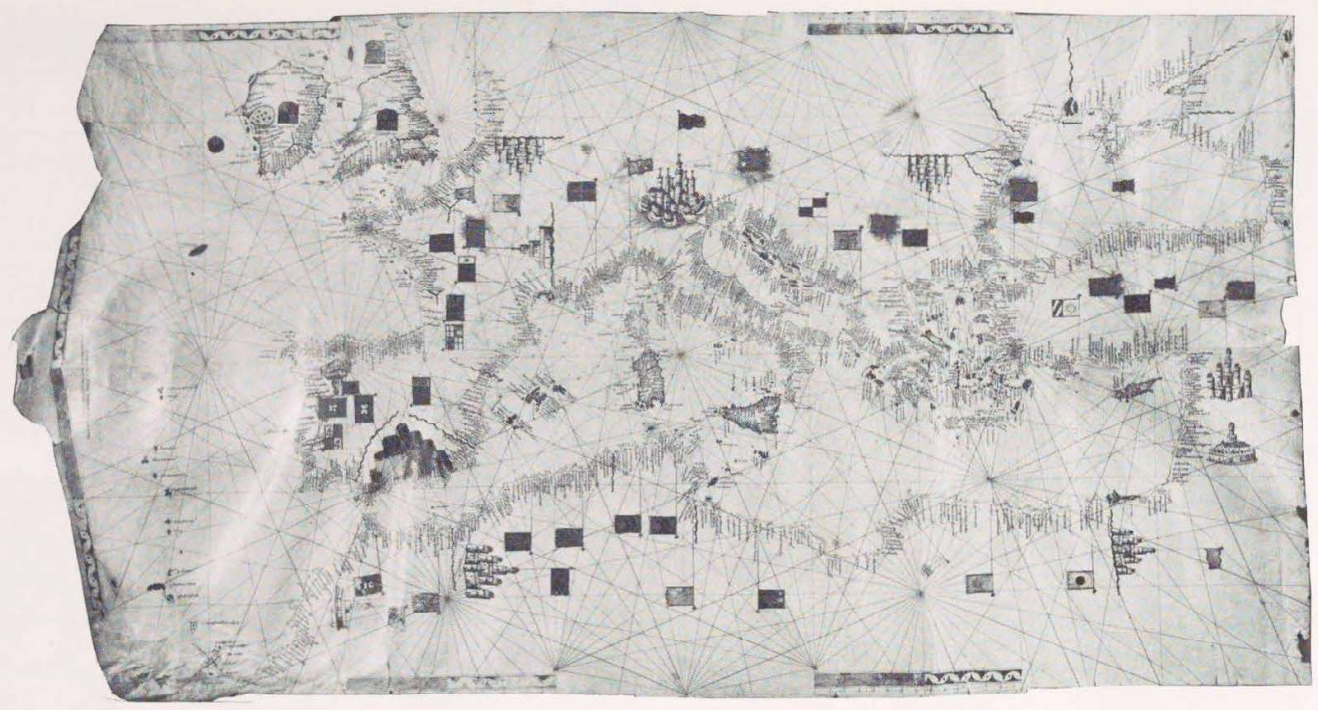

Astor, Lenox, and Tilden

Foundations.

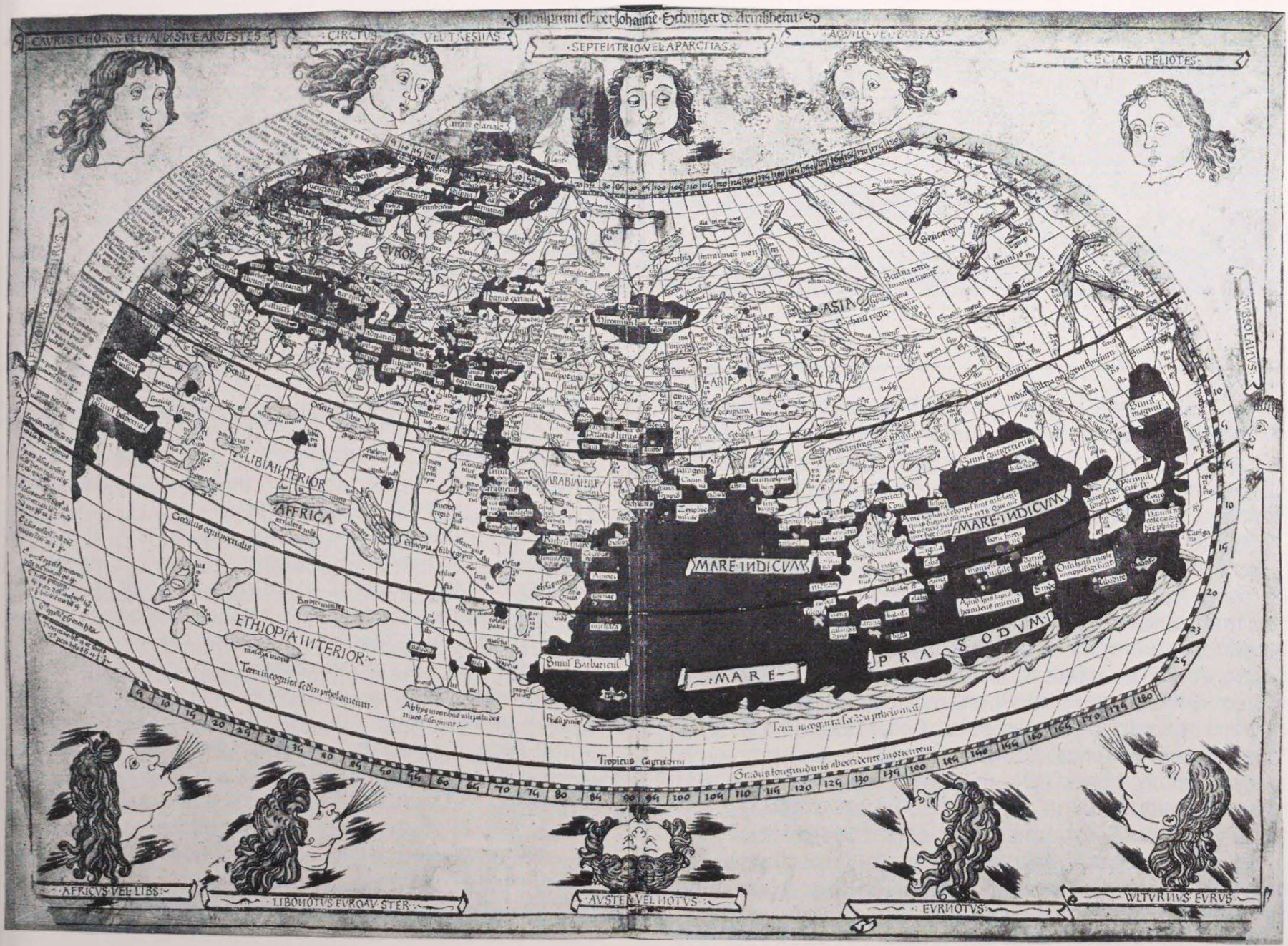




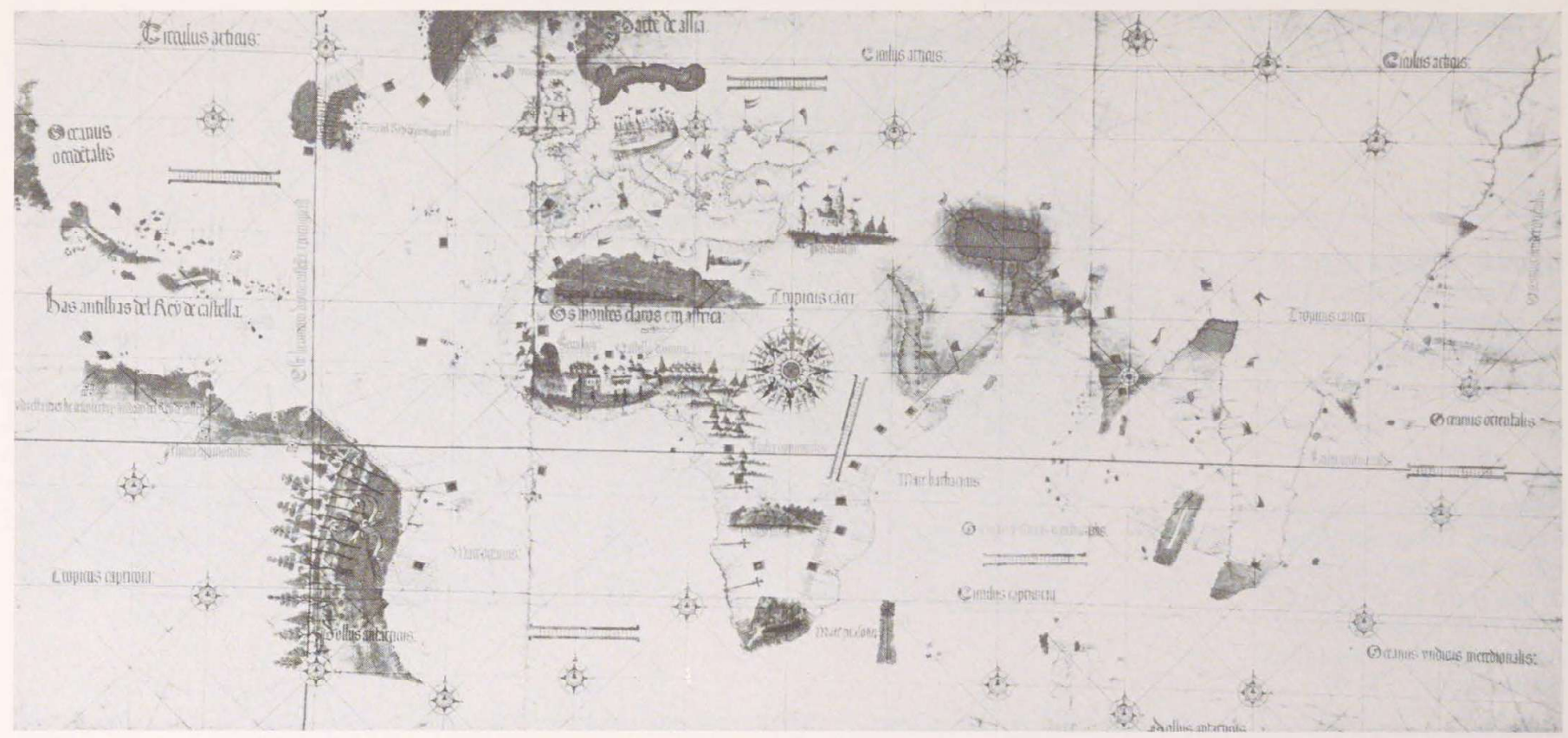

A Figure 7 Cantino manuscript map, 1502, from the Portugaliae Monumenta Cartographica. By permission of the Research Library, University of California, Los Angeles.
Figure 8 Ortelius, Typus Orbis Terrarum from the Theatrum, 1570. By permission of the Huntington Library, San Marino, California ing a "scientific" grid system for displaying a threedimensional earth on a two-dimensional piece of paper and using it to make more systematic empirical observations about geography (see Tooley 1978:6-7; Penrose, n.d.:255-261; Febvre and Martin 1976:248-252, 257-276)

Ironically, the out-of-date images of Ptolemaic geography were all too often considered more authoritative than accurate new data. This hampered the growth of an empirical geographical science and did not serve the Europeans who were looking for trade routes to the East. Ptolemy envisioned Africa as part of a great southern continent and had no idea that a fourth continent existed. But his world was an empirically measured one, systematically represented on a two-dimensional plane. Nothing could have been more useful to Europeans who needed to develop a visual language of property or territory in order to inventory their "discoveries" (see Eisenstein 1979:514-516).

The 1513 publication of Waldseemüller's Geographica, which added geographical information culled from the voyages of discovery to traditional Ptolemaic maps, was the next major move toward the new geography. It was important both because it made public information that had not been readily available before, and because it began to incorporate new findings in a larger system of scientific geography.
The world map in this volume seems drawn from a manuscript map of 1502, the Cantino map (Figure 7) (Penrose, n.d.:257-258, 277, 291-292; Tooley 1978:26), but while the Cantino map was drawn with a web of rhumb lines, the Waldseemüller maps are framed by the classical type of "scientific" grid based on measurements of latitude and longitude. In addition, the Waldseemüller maps contain new geographical data. The map of the Atlantic shows the shape of the New World even more clearly than the Cantino map. The work was a major cartographic breakthrough, but it also relied on relatively crude woodcut maps that were poor imitations of the subtle images commonly available on portolans. It was a start toward a new geography, not its most developed expression. 


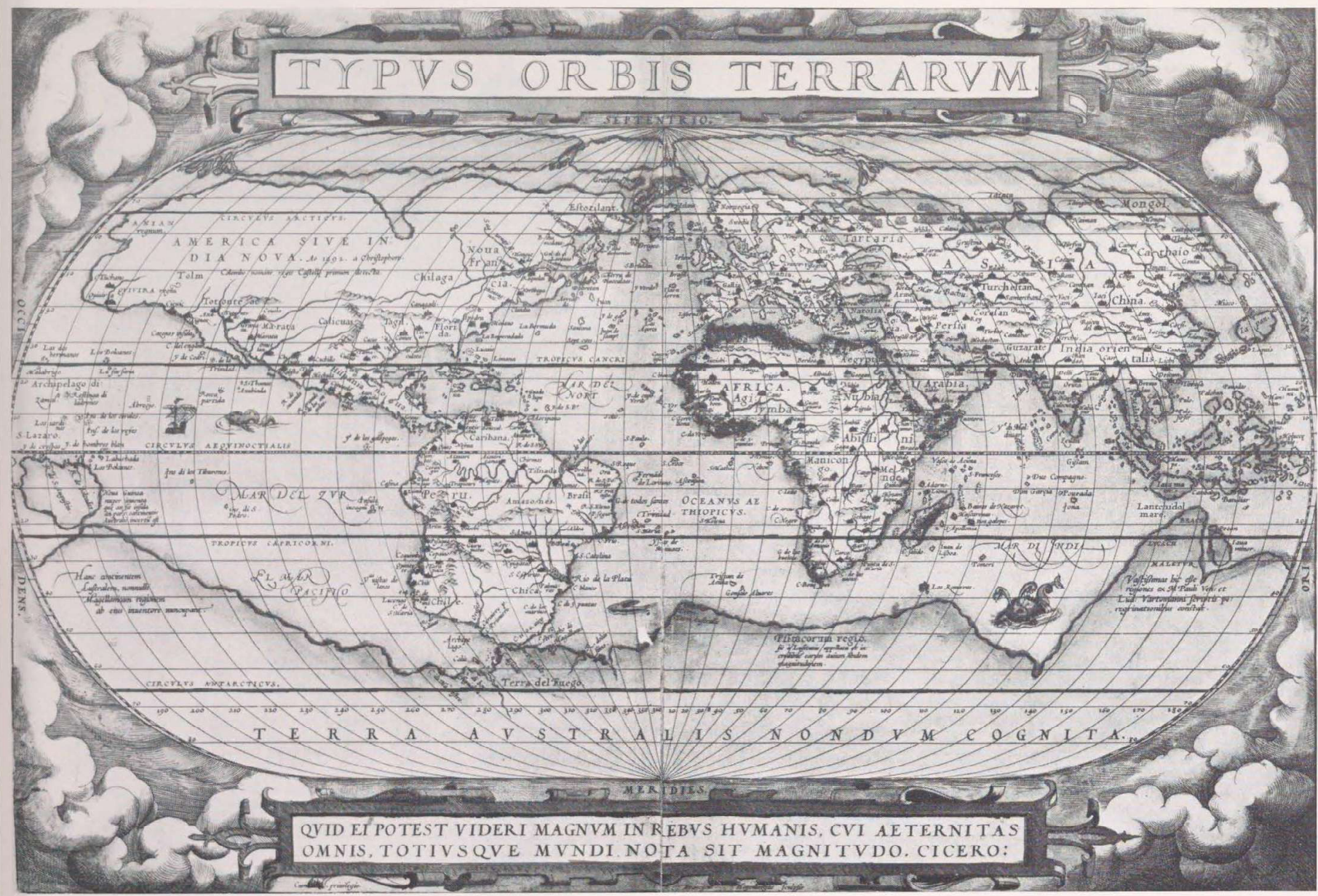

\section{Commercial Exploitation of Maps}

Systematic collection and distribution of detailed information about the coasts and continents began later during what has come to be called the Age of Atlases. In this period extensive collections of geographical details were made in greater quantity, not for the use of cosmographers or navigators alone but for a more general public. Carefully drawn maps were now frequently set in elaborately decorated books. Businessmen took the lead in geography, and what they provided seemed admirably suited to their commercial interests. Their highly decorated atlases and wall maps with an elaborate bricolage of images covered a range of European views of world geography and appealed to a wide range of tastes.

This experimentation with the commercial use of maps in the last half of the sixteenth century in the Netherlands led to an enormous growth of the map publishing business. It also produced two major atlases: the first published by Ortelius in 1570 and the second published by Mercator in the 1590s. Antwerp was the logical site for this kind of innovation because it was, before Charles V's death, the seat of the Habsburg empire. This empire joined together the two centers of European expansion, Spain and Portugal, so most new geographical information brought to light by expansion was likely to find its way to Antwerp.
Geographical publications were also likely to find an audience there, since many residents of that region had either an economic or an intellectual interest in understanding world geography (Wallerstein 1976:173-177; Steinberg 1959:104, 129-131)

Abraham Ortelius was in a good position to bring this information to the reading public. He was a lead ing cartographer and moved in the circle of people around the emperor; he also knew many cartographers in other parts of Europe. The atlas he produced (sec Figure 8) has been called the first truly modern atlas because it contained only contemporary geographical information, no Ptolemaic geography. It was drawn from regional maps, maps from the discoveries, and sailing charts (Crone 1953:chap. 8; Penrose n.d.:260-261; Lister 1970:chap. 2). In this sense it was a scientific or empirical atlas, but it was encyclopedic rather than selective. The maps within it were designed not to produce a simple model of geographical patterns but to record all available information about geography. In this way Ortelius's atlas bears strong resemblance to the Catalan atlas and the Ebstorf map, prescientific images of "totality." Even the idea of an atlas, the collection of all the world in one volume, suggests some residual influence of medieval encyclopedism. ${ }^{7}$

But there was also a fundamental modernity to Ortelius's work: he had the maps drawn in a system- 
atic way. The atlas form that Ortelius used was not original with him. Italians had collected maps of various sizes and styles and put them in a single publication. Ortelius improved on this practice by having all the maps in his atlas engraved in the same decorative style, showing their sources with citations at the bottom. His world map from the atlas is also drawn in a tight grid of latitude and longitude; the fact that the world is a globe is indicated by a roundness at the corners of the world map, but the frame of the images is clearly a grid. ${ }^{8}$ The modernity of Ortelius's geography is apparent in the familiarity of the world he depicts to the modern eye. Both Africa and Europe are easily recognizable; the Indian and South Asian peninsulas have come closer to their proper relationship than in Ptolemaic maps; and while the Spice Islands are oversized, they reflect an understandable

European interest in the area.

The decorative qualities of the atlas also help to identify it as a consumer item, designed with an eye to public sale. When Ortelius decided to reproduce the maps in a single style, he could just as easily have made the decision for commercial as for intellectual reasons. Similarly, the type of decoration Ortelius used for the map borders had both commercial and intellectual meaning. When I look at the background to the first edition of the world map, the swirling clouds or fog that surround the map and fill the space behind it, I am not only impressed by its decorative beauty but also by its power as a metaphor for the state of European cartography at that time. The world seems to have emerged from a fog through its "discovery." Interestingly, this type of border appeared in a number of maps of the period. Le Tetsu's map of the world of 1566 also has the hemispheres emerging from clouds (George 1969:196), Postel's woodcut map of 1581 cradles a polar projection of the world in clouds that protect this vulnerable circle from the severity of a rectangular frame (Shirley 1980:3), and de Jode's 1593 world map using a polar projection again fills the gap between circle and rectangle with clouds. ${ }^{9}$

This use of clouds can be read as an effort to place the world as a globe in the heavens. After all, clouds were commonly used to divide the celestial from the terrestrial in Baroque painting. But Ortelius also used clouds where he was ignorant of geographical details. North America is shrouded in fog, as is the great southern continent. These facts reinforce my first reading: that clouds are emblems of "the unknown," and what emerges from the border of clouds is the world becoming "known" through its mastery by European geographers. Perhaps these two interpretations can be merged if we see the world emerging here from the celestial sphere as knowledge of it is secularized.

This emerging world has become Europe's terri-

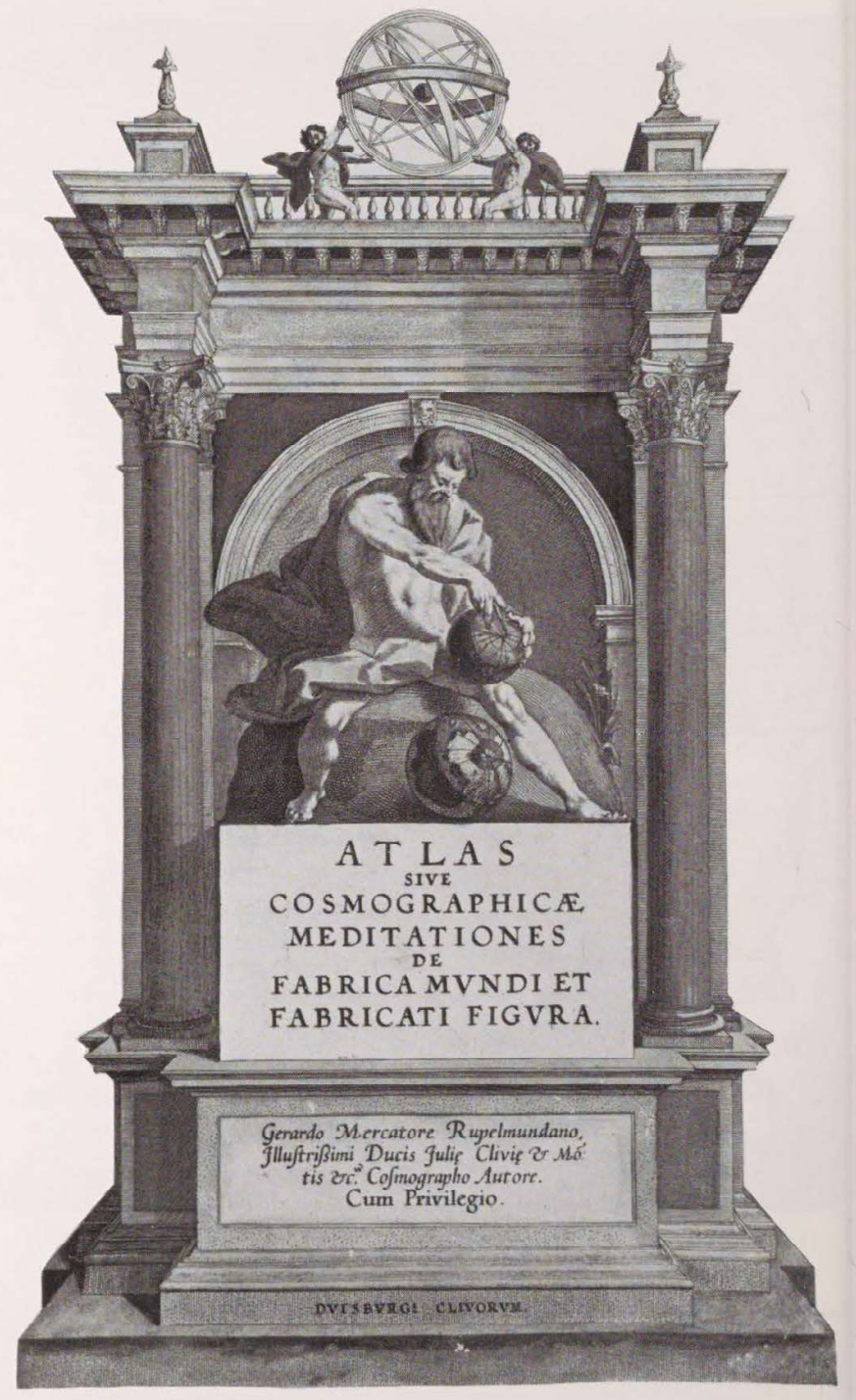

Figure 9 Mercator, title page to the Atlas. By permission of the William L. Clements Library, University of Michigan, Ann Arbor.

tory its property and focus of interest. The exagger ated size of the Spice Islands is evidence for this reading; the method for depicting political or economic centers is too. They are shown as castles on this map, as they were in the Catalan atlas, but here they are relatively small. Territories, rather than kings and tents, fill the continents; boundaries or edges are made visually more potent than centers. The division of land by boundaries is a modern Western convention based on the definition of land as private property, not as a common resource. So it is not just that Europeans learned more about the edges of continents, mountain ranges, rivers, and so forth, in this period, although that is true; they also paid attention to and cataloged the features of world geography that were important to them at home. As a result, atlases like this made the world a piece of European culture in two ways: by using European values to shape the language of maps and by using the power of maps to 


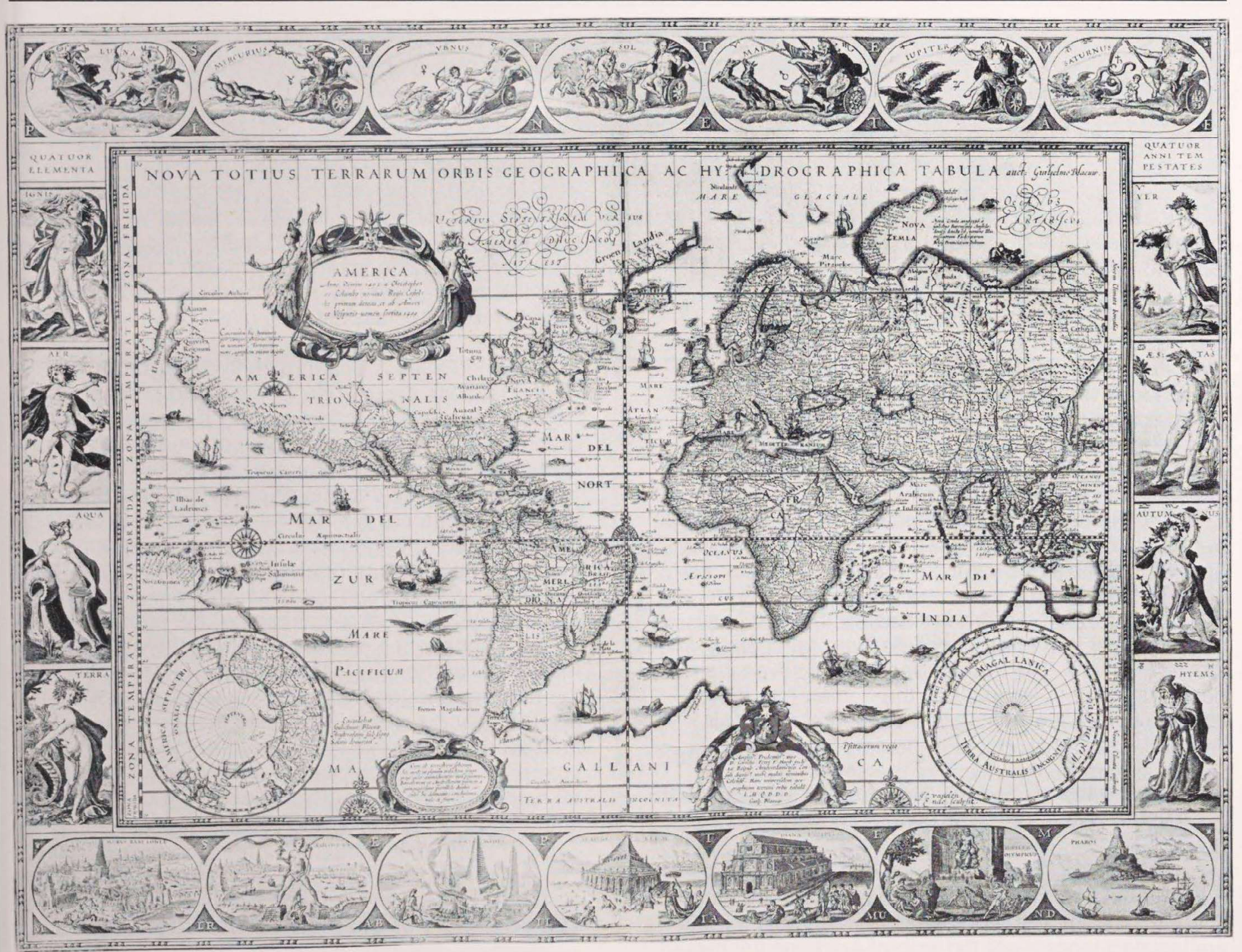

expand European domination of the world economy

The title page to Mercator's 1595 Atlas (Figure 9) illustrates most clearly the European sense of superiority to the world and its form. Atlas himself sits expectantly on the edge of his seat, not lifting the world as a burden on his shoulders but holding it like a basketball in his hands, measuring it with his fingers, tools, and eyes. The world is modeled below him in a globe that is not clearly related to the one above it; it seems perhaps the reproduction of it made ready for human exploitation. This world is not troublesome or mysterious. It is cute and only a little difficult to see because it is small. Atlas, as our surrogate, the symbol of Western culture in its encounters with earth, has taken the globe into a human space; he works in an arch of classical architecture that is on the one hand reminiscent of Raphael's "School of Athens" and on the other a ladder to the angels and the stars. ${ }^{10}$ The hubris of humanism pervades this image.
Figure 10 Blaeu, world map from the Novus Atlas. By permission of the Houghton Library, Harvard University, Cambridge, Massachusetts. 
Mercator's Atlas was a work of cultural hubris. Mercator developed a grid projection system for maps that compensated for the curvature of the earth in a new way. It allowed mariners to draw straight lines to chart their courses. His grid form made map use easier for the navigational interests, and thus his projection system seemed the perfect "scientific" form for European maps. Land could be recorded systematically in a grid, but the grid was designed to facilitate trade by simplifying navigation. Directionality in maps was joined to inventories of property in a single writing system. The fact that the atlas was first published with an incomplete set of maps at Mercator's death diminished its early commercial value. However, Jodicus Hondius acquired Mercator's plates, completed the atlas, and made this work a popular commodity as well as a recognized scientific achievement (Crone 1953:chap. 8; Penrose, n.d.:261-263; Lister 1970:chap. 2).

The sense of European domination of the world and ownership of its contents is again dramatically symbolized in the maps by Willem Blaeu and his successors. The 1606 world map, revised in 1641 (Figure 10 ), is a marvel of decoration and symbolism. The map's border is a tribute to civilization, particularly Western culture. The bottom depicts the seven wonders of the world-marvels of the human hand; the left side shows the Aristotelian elements: earth, air, fire, and water; the right side depicts the four seasons; and the top displays the seven planets as powers of the heavens. ${ }^{11}$ Numerology and imagery combine to harness human, natural, and supernatural power. The world is held in check by these powers, tamed by human mastery of them. There are European ships in all comers of the world. They may share this realm with sea monsters, but these threats are isolated terrors, not the kind of fundamental mysteries that the world had held for the author of the Ebstorf map. Even doubts about the interior of North America do not seem to be an embarrassment; Canada is covered with a cartouche that fills the space but does not cover European ignorance of the region. Its oval shape echoes the framing along the border of the map just as Ortelius's fog over North America reinforced and informed the use of clouds around his globe. But here the cartouches are emblems of Western culture that assert its dominance in spite of its limits.

The eclectic array of details marks this map as commercial/transitional. Climatic zones are marked out along with latitude and longitude, giving this map both of the types of grids used by the ancients; coastal landmarks are jammed along the continents as they were in portolans; and extensive information about the interiors of Africa and South America shows that new empirical observations have been added to these traditional sources of European geography.
Colonies or zones of influence are carefully placed and recorded, marking European expansion over world politics as well as geography; rivers and mountain ranges are found far into the interiors; and the inventories of plants, animals, peoples, and their dwelling patterns are rich, showing the partnership between expansion and the growth of sciences other than geography. Information is presented in almost unmanageable quantities, and the mixing of categories for analyzing information makes the encyclopedism here, like that in many atlases from this period, more preclassical than classical in form and effect.

The Blaeu atlas is a landmark in cartography precisely because it is so rich. It is a world presented between paradigms; it can take no background for granted. It is the logical outcome of an effort to accumulate geographical information and put it all in one place. It also suffers because there is no accepted system for organizing it. But its attention to the border of the page and boundaries of territories, along with the sumptuousness of presentation, show clearly the triumph of the commercial mind. This is a glorious commodity, a marvel of packaging; the attention to political boundaries reverberates with the attention to the border of the maps; the richness of design in both the borders and the maps themselves expresses symbolically the desire for wealth that drove Europeans to improve their cartography and fill the images of distant continents with images of their natural resources. The commercial language of maps is entrenched here, easily taken for granted. ${ }^{12}$

\section{The Beginning of Simplified Scientific Imagery}

Not surprisingly, simpler statements about geography were beginning to develop at this time. They were more specialized pieces that addressed one or two specific problems in even greater detail but took some basic geographical knowledge for granted. This more specialized and technical imagery comes closer to the kind of scientific imagery described by Latour.

The specialized maps made by Halley in the late seventeenth century are good examples of this newer, more scientific, genre. Halley's 1686 map of the trade winds (Figure 11) and his map of magnetic variations are visually more like the early $T$ and $O$ maps than Blaeu's world map in that they are simple line drawings without extensive decoration. The former follows the general lines of the trade winds over the world's oceans. That the winds are only shown on the oceans suggests the practical importance of the piece; it is clearly a useful kind of information for ocean sailing. Knowing how to use these winds efficiently in charting a course could prove extremely 


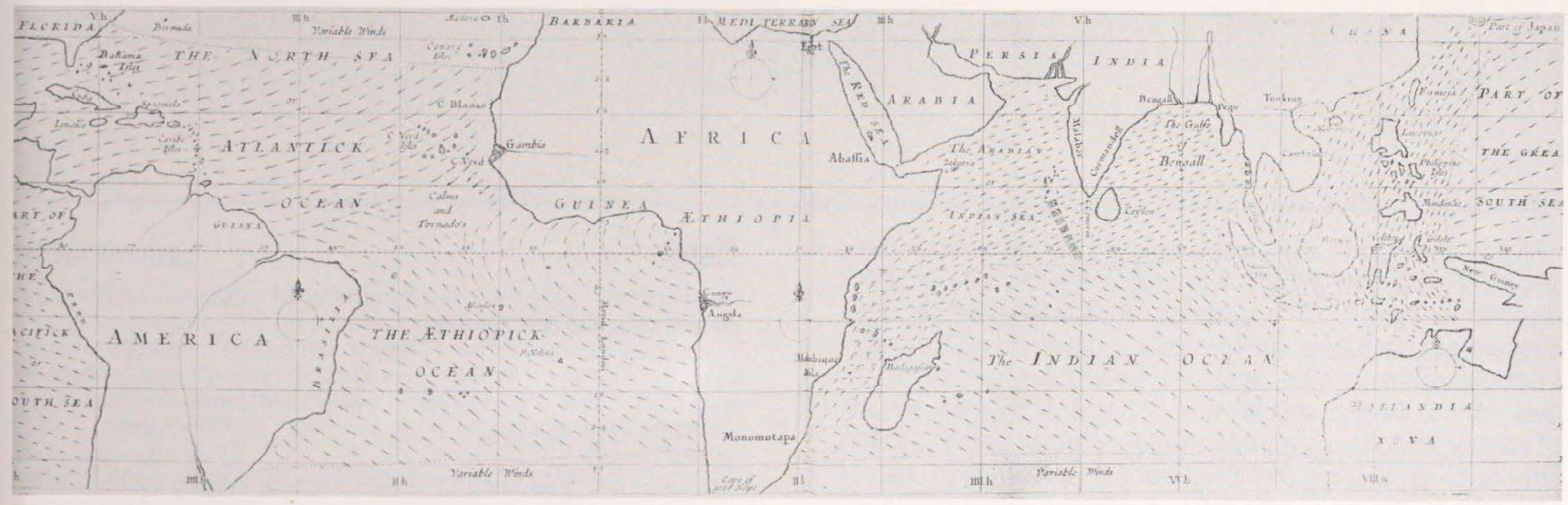

Figure 11 Halley, map of the trade winds, 1686. By permission of the British Library, London.

beneficial for navigators. Being able to consider this problem in isolation from others by designing a map devoted to just this subject also makes practical sense. The general outlines of the continents are here - all one would need to know about them while using the winds as "natural resources" for sailing.

Many of the same comments could be made about the map of magnetic variations. Efficient use of compasses, like the clever use of trade winds, was another pragmatic attempt to marry European technique with natural forces to improve ocean travel (and presumably to maximize profits in trade). European domination of the world's oceans and intercontinental trading remain the dominant themes in this map. The "scientific" image of the world presented here takes European struggles over the world economy for granted. This may not be apparent immediately because it no longer needs stating; competing systems for assigning meaning to the earth's form have been abandoned more or less. But this is one aspect of scientific simplification that becomes possible when the paradigm shift is complete.

Interestingly, a few decorative elements are maintained in this simpler, more measured world. Some palm trees, a few natives, a little drapery, and a light hand along the coasts give this map a nostalgic feeling; it alludes to the great decorated maps of a slightly earlier period, while beginning the movement toward a geography of specialists that required accuracy and geographical literacy from its readers. The public geography of the earlier era was dying here while it was being cited.

Wilma George's study of the images of fauna in European cartography is useful to consider here. She noticed a change in the character of the decoration on maps in this period. She found a great increase in the number of animals recorded in maps during the sixteenth century but a growing tendency by the end of this century to use particular animals as symbols of particular regions of the world. The elephant became a symbol for Africa; the opossum, toucans, and macaws came to represent South America. This kind of simplification of imagery on maps coincided with and to some extent predated the simplification of coastlines of the sort evident in Halley's map. Both came when scientific evidence was abundant and systematic records of data were commonplace. This kind of symbolism, while perhaps nostalgic, did not represent abandonment of the scientific project but its outcome. Some elements of information typical of earlier geography were sketched rather than depicted so that others could be presented in even greater detail. The paradigm finally allowed the mapmaker to rank the relevance of information for the record.

\section{Conclusions}

The movements in the depiction of geography described here between the twelfth and seventeenth centuries mark the growth of a mature, scientific geography in Europe. Some might call it the development of an empirical geography that made ideology secondary to direct observation. But that would be too simple a view. One system of ideology, religious imagery, was replaced by another: inventories of nature for politico-economic exploitation. Since the latter was more efficiently carried out with accurate measures of natural resources, it spurred the growth of an empirical science of geography. During the transition between paradigms, the inventories became increasingly complex and difficult to contain in a unitary form; this provided some pressure for maps to begin to be simplified and specialized. But the urge to simplify was not enough to make them that way. Simplification was possible when the primary visual language of maps became more conventional and maps could be moved back into the hands of experts. Further simplification gave scientific maps evolving forms, but it did not destroy the materialist assumptions of the geographical vision. It helped to fashion a more esoteric language for geography that served the interests of its new experts. 
A redefinition of European society at the end of the Middle Ages and the growth of capitalist trade and agriculture relied on increasing understanding of land-both its forms and possible uses. For nature to become open to new uses, it had to be understood in new terms. And a substantial change of interpretation of nature required an institutional reorganization of scholarship. During the long period of transition, geography found its sponsors in business and the state. It necessarily became a more public form of study; the new ways of thinking about geography were tried out for usefulness and market appeal. Once the commercial values determining the usefulness of geography to the politico-economy were incorporated into the language of maps itself, then maps were returned to the world of experts. With this step, early modern Europeans made the world theirs in symbol and to some degree in fact. What we read in old maps tells us this; what others once read in them three and four centuries ago helped to make this true.

\section{Notes}

1 Bruno Latour first pointed out the decline of simplicity in these maps to me, and I am grateful that he did

Eisenstein quotes Brown (1960) on the lack of progress in maps and cites Sarton on the strange interest in nonempirical symbolism as well as direct observations in maps of the period. Perhaps both could be seen as artifacts of this bricolage. See Eisenstein 1979:478-484.

2 For a discussion of scientific materialism, see Mukerji 1983.

3 The distribution of this information was not completely dominated by commercial values, since religious and economic rivalries were influencing patterns of trade.

4 See, for instance, Elliott 1970; Febvre and Martin 1976; Bucher 1981.

5 A similar configuration is in the Hereford map and to some extent the thirteenth-century "Psalter" world map.

6 This is a point I made in an earlier paper (see Mukerji 1978:241-252). There is ample evidence of fabrication by travelers in the Mandeville stories and many other bits of medieval travel writing. And there is plenty of evidence that this trend continued, albeit somewhat abated, into the early modern period. See Bucher 1981, chap. 2; Febvre and Martin 1976, chap. 2; Beaglehole 1966.

7 The encyclopedism of medieval and enlightenment Europe differed in ways that Foucault captured best in The Order of Things. The systematic effort to accumulate all the great ideas of civilization in the eighteenth century differed markedly from earlier efforts to record all kinds of information together, even when they bore little relationship to one another. For Foucault the latter is the hallmark of prescientific thought.

8 The solidity of a globe in contrast to the circle makes it less appropriate as a symbol of spiritual perfection.

9 Polar projection was a popular form for mapmaking in the sixteenth and seventeenth centuries. It seems a wonderful example of how Europeans accommodated the circle and the grid at the same time and in the same images during the transition period. These maps drew the world as a circle but one divided by a kind of grid structure. See Shirley 1980

10 My thanks to Cesar Graña for pointing out the relationship between Raphael's painting and this title page. I should also point out that images of Atlas are not always like this. He is not consistently in such control of the world. Cornelius Wytfliet's map of the hemispheres in his atlas of America shows Atlas bearing the world as a burden overhead. He kneels below it with modestly turned-down eyes, but he holds the two hemispheres with his fingers, not his arms or shoulders. And he is less important as a decorative image than as a cartouche at the top of the map that asserts with authority that this is in fact the map of the hemispheres.

11 It is interesting to compare the use of the seasons and elements in sixteenth- and seventeenth-century maps to the use of Noah's sons in maps during the late Middle Ages. The thought of the ancients takes the place of sacred texts. Moreover, the power of nature and human efforts to understand and control that power take the place of the power of God

12 Some John Speed maps and Danckerts's map of 1680 are similarly sumptuous and powerfully framed, suggesting that seventeenthcentury decorative maps often shared these features. The commercial mentality depicted in maps of the late seventeenth and early eighteenth centuries is almost parodied by George Willdey's map of North America. The map is dedicated to King George; an inscription on a monument states that this is the case. A miniature of King George is also suspended in the clouds overhead with an angel, putti, and a figure of Mercury. Beside the monument stands a female Indian, symbolizing America. At her feet are images of tobacco, pineapples, and snakes, symbolizing good fortune. Below this scene is a picture frame surrounding a variety of consumer goods-from combs, forks, knives, and purses to globes and reading glasses. These items are displayed neatly above the words, these and many other useful curiosities are made and sold wholesale and retail at the Great Toy Shop by G. Willdey" (University of Michigan Museum of Art 1979). 


\section{References}

- Antal, Frederick

1947 Florentine Painting in Its Social Background. London: Kegan Paul.

- Arnheim, Rudolf

1982 The Power of the Center. Berkeley: University of California Press.

- Baxandall, Michael

1974 Painting and Experience in Fifteenth-Century Italy. New York: Oxford University Press. Originally published 1972

- Beaglehole, John

1966 Exploration of the Pacific. 3d ed. Stanford: Stanford University Press.

- Brown, Lloyd

1960 Map Making. Boston: Little, Brown \& Co

- Bucher, Bernadelle

1981 Icon and Conquest. Chicago: University of Chicago Press

- Burckhardt, Jacob

N.d. Civilization of the Renaissance in Italy. New York: Oxford University Press.

- Certeau, Michel de

1980 Narratives of Space. Paper presented at the conference Space, Sign, and Subject. Davis, California.

- Crone, G. R.

1953 Maps and Their Makers. London: Hutchinson Library

- Eisenstein, Elizabeth

1979 The Printing Press as an Agent of Change. New York: Cambridge University Press.

- Elliott, J. H

1970 The Old World and the New. Cambridge: Cambridge University Press.

- Evelyn, John

1674 Navigation and Commerce. London: Benjamin Tooke.

- Febvre, Lucien, and Henri-Jean Martin

1976 The Coming of the Book. David Gerard tr. London: NLB. Originally published 1958

- Foss, Michael

1974 Undreamed Shores. New York: Charles Scribner's Sons

- Foucault, Michel

1979 Discipline and Punish. New York: Vintage.

1980 Power/Knowledge. Colin Gordon, ed. and tr. Brighton, England: Harvester Press.

- George, Wilma

1969 Animals and Maps. Berkeley and Los Angeles: University of California Press.

- Latour, Bruno

1982a The Importance of Studying Inscription Devices. Paper presented at the Society for Social Studies of Science Meeting. Philadelphia, $\mathrm{Pa}$.

1982b Give Me a Laboratory and I Will Raise the World. In New Perspectives in the Sociology of Science. K. Knorr and M. Mulkay, eds. Los Angeles: Sage.

a and Steve Woolgar

1979 Laboratory Life. London and Beverly Hills: Sage.

- Linschoten, John Huighen van

1598 His Discourse of Voyages into Ye Easte and Weste Indies. London: John Wolfe.

- Lister, Raymond

1970 Antique Maps and Their Cartographers. London: G. Bell.

- Mukerji, Chandra

1978 Bullshitting: Road Lore among Hitchhikers. Social Problems 3:241-252.

1983 From Graven Images: Patterns of Modern Materialism. New York: Columbia University Press.

- Parry, J. H

1963 The Age of Reconnaissance. Berkeley and Los Angeles: University of California Press
- Penrose, Boise

N.d. Travel and Discovery in the Renaissance. Cambridge: Harvard University Press.

- Petty, Sir William

1967 The History of the Survey of Ireland Commonly Called the Down Survey. New York: Augustus M. Kelley. Originally published 1851

- Pointer, Simon

1978 How Art Overcame Adversity. The Map Collector 2:7-14.

- Schilder, Gunter

1980 Cartographic Relations between Italy and the Low Countries in the Sixteenth Century. The Map Collector 4:2-8

1981 Some Decorative Maps of Holland 1569-1610. The Map Collector 5:21-28.

- Shirley, Rodney

1980 All the World within a Circle. The Map Collector 4:2-11.

- Smith, Thomas

1978 Manuscript and Printed Sea Charts in Seventeenth-Century London: The Case of the Thames School. In The Compleat Plattmaker. Norman Thrower, ed. Berkeley and Los Angeles: University of California Press. Chap.?

- Steinberg, $\mathrm{H}$.

1959 Five Hundred Years of Printing. New York: Criterion.

- Taylor, E. G. R

1971 The Haven-Finding Art. New York: Elsevier

- Thrower, Norman H.

1972 Maps and Man. Englewood Cliffs, N.J.: Prentice-Hall.

- ed.

1978 The Compleat Plattmaker. Berkeley and Los Angeles: University of California Press.

- Tooley, R. V.

1978 Maps and Map-Makers. New York: Crown. Originally published 1949

- University of Michigan Museum of Art

1979 Art à la Carte: Decorative Imagery in Maps, 1600-1800. Ann Arbor: University of Michigan Museum of Art.

- Vecellio, Cesare

1977 Vecellio's Renaissance Costume Book. New York: Dover. Originally published 1598

- Wallerstein, Immanuel

1976 The Modern World-System. London: Academic Press.

- Wallis, Helen M

1978 Geographie Is Better than Divinitie. In The Compleat Plattmaker. Norman Thrower, ed. Berkeley and Los Angeles: University of California Press. Chap. 1

- Woodward, David

1978 English Cartography, 1650-1750. In The Compleat Plattmaker. Norman Thrower, ed. Berkeley and Los Angeles: University of California Press. Chap. 5. 